\title{
Beyaz Önlük veya Yeşil Ameliyathane Önlüğü Giyen Hekim Tarafından Yapılan Muayenenin Preoperatif Dental Anksiyete Üzerine Etkisinin Karşılaştırılması
}

\section{Comparison of the Effect of the Examination Performed by a Physician Wearing a White Coat or Green Scrubs on Preoperative Dental Anxiety}

\author{
Kübra YAKUT ${ }^{* 1}$ (D) \\ kubrayakut.94@gmail.com
}

Bozkurt Kubilay IŞIK ${ }^{1}$ (D)

kisik@erbakan.edu.tr

\begin{abstract}
öz
Amaç: Hekimin geleneksel beyaz önlük veya ameliyathane önlüğü giymesinin preoperatif dental anksiyete üzerine etkisinin karșlaștırılması.

Gereç ve Yöntemler: Diş çekimi için başvuran yetişkin hastalardan, 60 hasta çalışmaya dahil edildi (27 erkek ve 33 kadın; yaş aralığı 18-65, ortalama yaş $42 \pm 12,27$ ). Hastalar rastgele iki gruba ayrıldı ve hepsi aynı hekim tarafından muayene ve tedavi edildi. Bu hekim bir grupta tüm çalışma boyunca uzun kollu beyaz önlük (Grup 1, n=30) diğer grup ise uzun kollu yeşil ameliyathane önlüğü giydi (Grup 2, n=30). Anamnez alındıktan sonra ve muayeneden önce, her iki grupta da kaygı seviyesi $100 \mathrm{~mm}$ uzunluğunda yatay bir çizgiden oluşan görsel analog skala ile ölçüldü ve "1. ölçüm" olarak kaydedildi. Lokal anestezi yapıldıktan sonra $5 \mathrm{dk}$ beklendi, anksiyete seviyesi tekrar ölçüldü ve "2. ölçüm" olarak kaydedildi. Verilerin normal dağılıma uyumuna Shapiro-Wilk testi ile bakıldı ve gruplar arası karşılaştırma için t testi, grup içi karşılaştırmalar için eşleştirilmiş t testi yapıldı. İstatistiksel önem seviyesi $\mathrm{p}<0,05$ olarak belirlendi.

Bulgular: Grup 1'deki hastaların ilk anksiyete seviyeleri Grup 2'den önemli miktarda daha fazlaydı $(\mathrm{p}<0,05)$. Her iki grupta da ikinci ölçümde anksiyete seviyesinin anlamlı derecede azaldığı gözlendi $(p<0,05)$. Öte yandan anksiyete seviyesinin ikinci ölçümlerinde ise gruplar arasında fark kalmamıştı $(p>0,05)$.

Sonuç: Sifır hipotezi reddedilmiştir. Hekimin beyaz önlük giymesi ile yeșil ameliyathane önlüğü giymesi kıyaslandığında yetişkin hastalarda başlangıçta yol açtığı anksiyete miktarı farklıdır. Beyaz önlük yeşil ameliyathane kıyafetine göre daha fazla anksiyeteye yol açmaktadır. Aşırı anksiyeteli hastalarda beyaz önlük giymekten kaçınmak düşünülebilir.
\end{abstract}

Anahtar Kelimeler: Anksiyete, Dental anksiyete, Diş hekimi, Diş hekimi kıyafeti

Geliş: 01.10.2020

Kabul: 16.12.2020

Yayın: 31.12.2020

\begin{abstract}
Aim: To compare the effect of the traditional white coat or green scrubs on preoperative dental anxiety.

Material and Methods: Among adult patients who applied for tooth extraction, 60 patients were included (27 males, 33 females, age between 18 and 65 , mean age $42 \pm 12.27$ ). They were randomly divided into two groups and all the patients were examined and treated by the same physician. The physician wore a traditional long sleeved white coat in the first group (Group 1, n=30), and a long sleeved green scrubs in the second group (Group 2, n=30). After the medical history was taken and before the clinical examination, anxiety level of the patient was measured with a $100 \mathrm{~mm}$ visual analogue scale and recorded as " 1 . measurement". After the local anesthesia was done, we waited for 5 minutes and the anxiety level was measured again and recorded as " 2 . measurement". The compliance of the data to the normal distribution was examined by Shapiro-Wilk test, and t test was used for intergroup comparison and paired t test was employed for intragroup comparisons.

Results: The initial anxiety levels of the patients in Group 1 were significantly higher than that of Group 2 ( $p<0.05)$. In both groups, the anxiety level significantly decreased in the second measurement $(p<0.05)$. On the other hand, in the second measurements, there was no significant difference between the groups $(\mathrm{p}>0.05)$.

Conclusion: The null hypothesis was rejected. In adult patients, wearing a white coat or green scrubs cause different anxiety levels at the beginning of the dental treatment. A traditional white coat causes more anxiety than green scrubs in adult patients. Avoiding to wear a white coat might be taken into consideration in the patients with severe anxiety.
\end{abstract}

Keywords: Anxiety, Dental anxiety, Dentist, Dentist's outfit

Received: $01.10 .2020 \quad$ Accepted: $16.12 .2020 \quad$ Published: 31.12 .2020

Atıf / Citation: Yakut K, Işı BK. Beyaz önlük veya yeșil ameliyathane önlüğü giyen hekim tarafından yapılan muayenenin preoperatif dental anksiyete üzerine etkisinin karşılaștırılması. NEU Dent J. 2020;2:113-6.

* Sorumlu Yazar / Corresponding Author

1. Necmettin Erbakan Üniversitesi Diş Hekimliği Fakültesi Ağız, Diş ve Çene Cerrahisi AD Konya, Türkiye 


\section{GíRiş}

Humphris anksiyeteyi tanımlarken "neredeyse her zaman için etkisinin dağılması zaman alan belirli bir olayla ilişkili ve deneyimlemesi hoş olmayan, endişe verici bir psikolojik yapı" olarak ifade eder. ${ }^{1}$ Diş hekimliğine yönelik anksiyete çok yaygındır, "önleyici bakım yahut diş tedavisi için diş hekimini ziyaret etmeye veya diş prosedürlerine karşı oluşan anormal bir korku" olarak tanımlanmıștır". ${ }^{2}$ Dental anksiyetenin bilișsel, davranıșsal ve fizyolojik sonuçları olabilir. Yapılan bir çalışmada yetișkin nüfusun üçte biri kendilerini diș hekimine karșı endișeli olarak tanımlamıștır. Ayrıca üzerinde çalışılan bu grubun \%43'ü diş hekimine gitmekten çekinmekte ve grubun \%58'i bunun sebebini "diş hekiminden korkmak" olarak ifade etmektedir. ${ }^{3}$

Dental anksiyete ayrıca diş hekiminin çalışma ortamını da etkiler. Endişeli hastalarla başa çıkmaya çalışmak performansı düşürür, gerginliği artırır, seans başına daha uzun süreler gerekir. Dental anksiyeteyle başa çıkmak, pek çok diş hekimi için en zor görevlerden biridir. ${ }^{2-4}$

Bazı araştırmacılar diş hekimlerinin dış görünüşünün dental anksiyeteyi etkileyebileceğini ve gözlük, eldiven, maske, siper gibi kișisel koruyucu ekipmanların hastalarda anksiyeteyi artırdığını savunmaktadır. ${ }^{5}$ Hekim dış görünüşü ve dental anksiyete etkileşimiyle ilgili araştırmalar çoğunlukla çocuklar üzerinde yoğunlaşmıştır ${ }^{6}$ ve yetişkinler için yapılan çalışma sayısı azdır.

Biz bu çalışmada hekimin tedavi sırasında giydiği formanın yetișkin oral cerrahi hastalarının ișlem öncesi dental anksiyete seviyesi üzerine etkisini araştırdık.

\section{HASTALAR VE YÖNTEM}

Bu çalışma için kurumumuzdan etik kurul onayı alınmiştır. Kliniğ́imize 06.07.2020 ve 17.07.2020 tarihleri arasında diş çekimi için başvuran hastalardan aşağıdaki kriterlere uyan rastgele 60 hasta çalıșmaya dahil edildi (27 erkek, 33 kadın).

Dahil etme kriterleri:

- Ayakta tedavisi yapılan hastalar

- 18 yaşından büyük hastalardır.

Hariç tutma kriterleri:

- Genel anestezi ile işlem yapılması gereken hastalar

- Lokal ameliyathane ortamında işlem yapılması gereken hastalar

- Psikiyatrik sorunlu hastalar

- Pediatrik hastalar.

Hastaların yaşları 18 ile 65 arasında değişmekteydi (ortalama $42 \pm 12,27$ ). Hastalar her birinde 30 kişi olmak üzere rastgele iki gruba ayrıldı. İlk grupta tüm çalışma boyunca hekimin üzerinde beyaz önlük vardı (Grup 1). Diğer grupta ise hekim yeşil ameliyathane önlüğü giymekteydi (Grup 2). Anksi- yete düzeyini etkileme ihtimaline karşı, hastayla ilk karşılaşmadan itibaren çalışmanın devamı boyunca yasal ve etik bilgilendirmeler dișında iletișime geçilmedi. Yine anksiyete düzeyini etkileyebilecek ses, müzik, görseller ve kimyasal kokular klinikte bulundurulmadı.

Her iki grupta da klinik muayene yapılmadan önce anamnez alındı ve ilk kaygı seviyesi görsel analog skala (GAS) ile ölçüldü. GAS $100 \mathrm{~mm}$ uzunluğunda yatay bir çizgiden oluşmaktaydı. Çizginin sol ucunda "hiç kaygım yok", sağ ucunda ise "korkunç derecede kaygllıyım" yazmakta, üzerinde bașkaca numara veya yazılar bulunmamaktaydı. Hastalar anksiyete seviyesini bu çizgi üzerinde işaretledi ve bu noktanın sol uca olan uzaklığı milimetre cinsinden ölçüldü. Buna "1. ölçüm" denildi. Anestezi yapıldıktan sonra hastanın görüș alanında kalacak șekilde, kendisiyle iletişime geçmeden $5 \mathrm{dk}$ beklendi. Bu sürenin sonunda GAS ile ikinci kez anksiyete seviyesi ölçüldü ve "2. ölçüm" olarak kaydedildi. Daha sonra hastanın tedavisi rutin olarak tamamland..

\section{İstatiksel Analiz}

Birinci ve ikinci ölçüm GAS skorları istatistiksel olarak karşılaștırıldı. Bu amaçla SigmaPlot 14.0 istatistik yazılımı (Systat Software, San Jose, CA) kullanıldı. Verilerin normal dağılıma uyumuna Shapiro-Wilk testi ile bakıldı ve gruplar arası karşılaștırma için $\mathrm{t}$ testi, grup içi karşılaştırmalar için eşleștirilmiş t testi yapıldı. İstatistiksel önem seviyesi 0,05 olarak belirlendi.

\section{BULGULAR}

Anksiyete seviyelerinin 1. ve 2. ölçümleri gruplar arasinda ve her bir grubun kendi içinde karşılaştırıldı.

Grup 1'deki hastaların ilk anksiyete seviyeleri Grup 2'den daha fazlaydı $(\mathrm{p}<0,001)$ (Tablo 1).

Tablo 1: Birinci ölçümlerin gruplar arası karşılaştırılması

\begin{tabular}{|lcc|}
\hline & Ortalama & Standart sapma \\
\hline Grup 1, 1. ölçüm & 4,000 & 1,971 \\
\hline Grup 2, 1. ölçüm & 2,367 & 1,916 \\
\hline
\end{tabular}

Anksiyete seviyesinin ikinci ölçümlerinde ise gruplar arasında anlamlı bir fark kalmamıştı $(p=0,060)$ (Tablo 2).

Tablo 2: İkinci ölçümlerin gruplar arası karşılaștırılması.

\begin{tabular}{|lcc|}
\hline & Ortalama & Standart sapma \\
\hline Grup 1, 2. ölçüm & 2,460 & 2,315 \\
\hline Grup 2, 2. ölçüm & 1,637 & 1,665 \\
\hline
\end{tabular}

Grup 1'de ilk ölçümden beș dk sonra alınan ikinci ölçümde anksiyete seviyesinin anlamlı derecede azaldığı gözlendi $(\mathrm{p}<0,001)$ (Tablo 3$)$. 
Tablo 3: Grup 1'de birinci ve ikinci ölçümlerin karşılaștırılması.

\begin{tabular}{|lcc|}
\hline & Ortalama & Standart sapma \\
\hline Grup 1, 1. ölçüm & 4,000 & 1,971 \\
\hline Grup 1, 2. ölçüm & 2,460 & 2,315 \\
\hline
\end{tabular}

Benzer șekilde, grup 2'de de anksiyete seviyesi ikinci ölçümde önemli derecede azalmıștı ( $\mathrm{p}=0,003)$ (Tablo 4).

Tablo 4: Grup 2'de birinci ve ikinci ölçümlerin karşılaștırılması

\begin{tabular}{|lcc|}
\hline & Ortalama & Standart sapma \\
\hline Grup 2, 1.ölçüm & 2,367 & 1,916 \\
\hline Grup 2, 2. ölçüm & 1,637 & 1,665 \\
\hline
\end{tabular}

İstatistiksel analizlerin gücü t testi için \%75, eşleştirilmiş t testi için \%70 olarak bulundu.

\section{TARTIŞMA}

Psikolog ve sosyologlar görünüşün önemi üzerinde durmuş ve bunun ilk izlenimler, kișilerarası ilișkiler ve iletişim üzerindeki etkisini vurgulamıștır. ${ }^{7}$ Dunn ve ark. ${ }^{8}$ fiziksel görünümün hekim-hasta ilişkisinin gelişmesinde ve bir bireyin aile hekimi seçiminde çok önemli olduğunu belirtmektedir. Bahsi geçen fiziksel görünümü oluşturan etkenlerin bir kısmını da önlük ve kişisel koruyucu ekipmanlar meydana getirir. Diş görünüşü oluşturan bu unsurlar yalnızca hekimi korumakla kalmayıp aynı zamanda kişilerin hekime bakış açısını etkilemekte ve hastaların tedavi sürecindeki anksiyete seviyesinin belirlenmesinde de etkili olmaktadır.

Anksiyete seviyesini etkileyen faktörler çok fazla etkene bağlı olabilir ve bu etkenler büyük ölçüde farklılık gösterse de diş hekimlerinin uygun kıyafet seçimi onların hastanın istek ve duygularını anlamasına katkıda bulunabilir.9 Barrett ve Booth ${ }^{10}$ geleneksel beyaz önlüğün çocuk hastalar üzerinde olumsuz bir etki oluşturduğunu ilk bildirenlerdendir ve çocukların, daha resmi olan bu giyim tarzı sebebiyle doktorları daha yetkin olarak gördüklerini ancak onları arkadaşça bulmadıklarını söylemektedir, bu durum çocukların hekime karşs güven içerisinde ve ciddi bir etkileşimde olmasını sağlayabilir.

Ağız diş ve çene cerrahisinde bilinçli sedasyon ve genel anestezi anksiyeteyi yönetmenin yaygın yollarından biridir. Fakat bu prosedürler bir miktar risk taşımakla birlikte, özel bilgi ve ekipman gerektirir. Bu yöntemlerin herhangi bir diş kliniğinde rutin olarak uygulanması ise mümkün değildir. ${ }^{11}$ Dolayısıyla farmakolojik olmayan yöntemlerle anksiyetenin azaltılması her zaman değerini koruyacaktır. İște bu yöntemlerden biri de hekimin dış görünüşünü şekillendirmektir.

"Palyaço doktorların" pediatride ameliyat öncesi çocukların anksiyetesini azaltmada etkili olduğu görülmüștür. ${ }^{12}$ Cohen'in bir çalıșmasında ${ }^{13}$ gömlek, kravat ve beyaz ceket giymiş veya sadece gömlek ve kravat giymiş yahut klinik önlük giymiş diș hekimlerinin hastalarını incelediğinde, hastalardaki anksiyete düzeyleri açısından önemli bir fark gözlenmemiștir. Daha yakın zamanlarda Mistry ve Tahmassebi'ye göre ${ }^{14}$ ebeveynler, çocuklarıyla ilgilenecek diş hekimlerinin geleneksel beyaz önlük giymesini, çocuklar ise diş hekimlerinin gündelik kıyafet giymesini istemiştir. Kuşcu ve ark. ${ }^{15}$ biraz farklı bir sonuca ulaşmıș, çocukların da kendisiyle ilgilenecek diş hekimlerinin klyafet olarak beyaz önlük giymesini tercih ettiğini bulmuştur. Ancak çok endişeli çocuklar yine sempati uyandıran kıyafetlere öncelik tanımıştır. Diğer bazı araștırmalarda çocukların büyük çoğunluğu diş hekimlerinin beyaz önlük giymesini yeğlemiştir. ${ }^{14,16} \mathrm{Bu}$ bulgular McCarthy ve ark. ${ }^{17}$ tarafindan tespit edilen bununla birlikte Nair ve ark. ${ }^{18}$ tarafindan da desteklenen yaygın inanışın aksine, çocukların beyaz önlüklü hekimden korkmadıklarını ve daha resmi giyinmiş bir hekimi daha yetkin ve ilgili olarak gördüklerini ortaya koymuştur. Hatta çocuk hastaların koruyucu teçhizatı olan diş hekimlerinin kendisini tedavi etmesini istediğini gösteren çalışmalar da mevcuttur. ${ }^{19,20}$ Anlaşlacağ̆ üzere, hekimin klyafet tarzı hastanın algısını büyük ölçüde değiştirmektedir ve bu bilgi hekimin hasta üzerinde daha olumlu bir algı oluşturması için kullanılabilir. ${ }^{21}$

Mevcut araştırmalardan da görüldüğü gibi bu alanda yapılan çalışmalar genellikle çocuklar üzerinde yoğunlaşmıştır. Biz ise bu çalışmada hekim kıyafetlerinin erişkinler üzerindeki etkisini araştırdık. Bulgularımıza göre hekimi beyaz önlük ile gören hastalarda daha yüksek bir anksiyete seviyesi oluşmuştu. Açıkçası bu durum bizim beklentimizden farklıydı, çünkü yeşil önlüğün hastalarda "ameliyat" çağrışımı yaparak daha fazla strese yaratacağını düşünmüştük. Fakat anlaşıldığı kadarıyla klasik "doktor" imajı beyaz önlük ile daha güçlü biçimde ilişkilenmiş bulunmaktadır.

Hastanın görüş alanında 5 dakika bekledikten sonra her iki grupta da kaygı seviyesi kayda değer miktarda azalmıștır. Buradan hareketle, kaygı seviyesindeki düşüşü yalnızca hekimin kıyafet şekli değil hastanın kliniğe, yapılacak tedavinin korkusu ile gelmesi ve ortamda beklediği süre sonunda bu kaygının spontan olarak azalması, bir başka deyişle hastanın ortama alışmasına bağlayabiliriz.

\section{SONUÇ}

Alıșllagelmiș hekim kıyafeti olan beyaz önlük yetișkin hastalarda daha fazla anksiyeteye yol açmaktadır. Rutinde bu bir problem teşkil etmemekle birlikte aşırı dental anksiyetesi bulunan bireylerde göz önünde bulundurulmalı, beyaz hekim önlüğü yerine bașka renk ve tipte kıyafetlerin kullanımı düşünülmelidir. 


\section{KAYNAKLAR}

1. Humphris G, Ling MS. Behavioural sciences for dentistry. London: Churchill Livingstone; 2000.149 p.

2. Kritsidima M, Newton T, Asimakopoulou K. The effects of lavender scent on dental patient anxiety levels: a cluster randomised-controlled trial. Community Dent Oral Epidemiol. 2010;38(1):83-7.

3. Kleinknecht RA, Klepac RK, Alexander LD. Origins and characteristics of fear of dentistry. J Am Dent Assoc. 1973;86(4):842-8.

4. Kent GG, Blinkhorn AS. The psychology of dental care. 2nd ed. 1991. p. 1-28.

5. Glaros AG, Gadbury-Amyot CC. How personal protective equipment affects perceptions of dentists. J Am Dent Assoc. 1993;124(10):82-8; discussion 90.

6. Siegel LJ, Smith KE, Cantu GE, Posnick WR. The effects of using infection-control barrier techniques on young children's behavior during dental treatment. ASDC J Dent Child. 1992;59(1):17-22.

7. Berscheid E, Gangestad S. The social psychological implications of facial physical attractiveness. Clin Plast Surg.1982;9:289-96.

8. Dunn JJ, Lee TH, Percelay JM, Fitz JG, Goldman L. Patient and house officer attitudes on physician attire and etiquette. JAMA. 1987;257(1):65-8.

9. Thomas DP, Brett P. What is next in educational research? 2016. p. 285-95.

10. Barrett TG, Booth IW. Sartorial eloquence: does it exist in the paediatrician-patient relationship?. BMJ. 1994;309(6970):1710-2.

11. Coulthard P. Conscious sedation guidance. Evid Based Dent. 2006;7(4):90-1.

12. Vagnoli L, Caprilli S, Robiglio A, Messeri A. Clown doctors as a treatment for preoperative anxiety in children: a randomized, prospective study. J. Pediatr. 2005;116(4):563-7.

13. Cohen SD. Children's attitudes toward dentists' attire. J Dent Child. 1973;40(4):285-7.

14. Mistry D, Tahmassebi JF. Children's and parents' attitudes towards dentists' attire. EAPD. 2009.10: 237-40.

15. Kuscu 00, Çağlar E, Kayabaşoğlu N, Sandalli N. Preferences of dentist's attire in a group of Istanbul school children related with dental anxiety. EAPD. 2009.;10:38-41.

16. AlSarheed M. Children's perception of their dentists. Eur. J. Dent. 2011.5:186-90.

17. McCarthy JJ, Christine McCarthy M, Eilert RE. Children's and parents' visual perception of physicians. Clin Pediatr. 1999;38:145-52.

18. Nair BR, Mears SR, Hitchcock KI, Attia JR. Evidencebased physicians' dressing: a crossover trial. Med. J. Aust. 2002;177: 681-2.

19. Kelly GR, Shroff B, Best AM, Tufekci E, Lindauer SJ. Parents' preferences regarding appearance and attire of orthodontists. Angle Orthod. 2014;84(3):4049.
20. Shulman ER, Brehm WT. Dental clinical attire and infection-control procedures. Patients' attitudes. J Am Dent Assoc. 2001;132(4):508-16.

21. Kamavaram Ellore VP, Mohammed M, Taranath M, Ramagoni NK, Kumar V, Gunjalli G. Children and parent's attitude and preferences of dentist's attire in pediatric dental practice. Int J Clin Pediatr Dent. 2015;8(2):102-7. 